BATI'DA DOĞU'YU, DOĞU'DA BATI'YI ANLATAN ADAM: EĞİTIMCİ, AKADEMISYEN KÂMIL AYDIN VE ESERLERİ ÜZERINNE

Siddık BAKIR*

\begin{abstract}
Özet
Kâmil AYDIN yayımladığı Karşılaştırmalı Edebiyat (Günümüz Postmodern Bağlamında Algllanışı), Entelektüel Yabancılar ve Ölümcül Kimlikler (Saul Bellow ve Sylvia Plath) ile Images of Turkey in Western Literature adlı üç kitabı yanında, lisans ve lisansüstü düzeyde çeşitli dersler veren; İngiliz Dili ve Edebiyatı, İngiliz Kültürü, Avrupa Birliği, Türk Kültürü, Kültürler Arası İlişkiler, Doğu-Batı Arasındaki Sosyal ve Kültürel İlişkiler gibi konular üzerine yapmış olduğu başarılı çalışmalarıyla tanınan bir akademisyendir.

$\mathrm{Bu}$ makale esas itibarıyla araştırmacı, eğitimci, akademisyen Kâmil AYDIN'ın hayatını ve çalışmalarını konu almaktadır.

Anahtar kelimeler: Kâmil Aydın, entelektüel, karşılaştırmalı edebiyat, kültürel ilişkiler.

\section{THE MAN WHO TELL EAST IN WEST, WEST IN EAST: ABOUT PEDAGOGUE, ACADEMICIAN KAMIL AYDIN AND HIS WORKS}

\title{
Abstract
}

Besides his three books named Karşılaştırmalı Edebiyat (Günümüz Postmodern Bağlamında Algılanışı), Entelektüel Yabancılar ve Ölümcül Kimlikler (Saul Bellow ve Sylvia Plath) and Images of Turkey in Western Literature, Kâmil Aydın is an academician who teaches graduates and postgraduates and known with his successful studies on English Culture, European Union, Turkish Culture, Cross-cultural Relations, Cultural and Social Relations Between the East and the West.

This article mainly focuses on researcher, lecturer and academician Kâmil AYDIN's life and works.

Keywords: Kâmil Aydın, intellectual, comparative literature, cultural relations.

\section{Kâmil AYDIN'ın Öz Geçmişi:}

Kâmil AYDIN, 1963 yılında Erzurum İli Merkez İlçesi'ne bağlı Veyisefendi Mahallesi’nde dünyaya gelir. İlk ve ortaöğrenimini Erzurum'da tamamlar.

1985 yılında Atatürk Üniversitesi Fen-Edebiyat Fakültesi İngiliz Dili ve Edebiyatı Bölümü'nden mezun olur.

AYDIN, 1986 yılında Fullbright Eğitim Komisyonu tarafindan Robert College'de düzenlenen İngilizce yeterlilik kursunu başarıyla tamamlar.

\footnotetext{
* Okutman; Atatürk Üniversitesi, Yabancı Diller Yüksekokulu, SIDDIKBAKIR@ hotmail.com.
} 
1987 yılında Çağdaş Amerikan Romanı isimli ilk yüksek lisans çalışmasını yapar.

AYDIN, Ekim 1989'da lisansüstü öğrenim görmek üzere İngiltere'ye gider. Warwick Üniversitesi Çeviri-Mütercimlik ve Karşılaştırmalı Edebiyat Bölümünde Karşılaştırmalı Edebiyat Kuramı isimli ikinci yüksek lisans çalışmasını 1991 yılında tamamlar.

20. Yüzyıl Batı Kaynaklarında Türkiye İmgesi isimli doktora çalışmasını aynı üniversitede Aralık 1994 tarihinde sonuçlandırır. Söz konusu çalışma hem British Council (1999) hem de Eothen Press (2000) tarafindan kitap olarak yayımlanır.

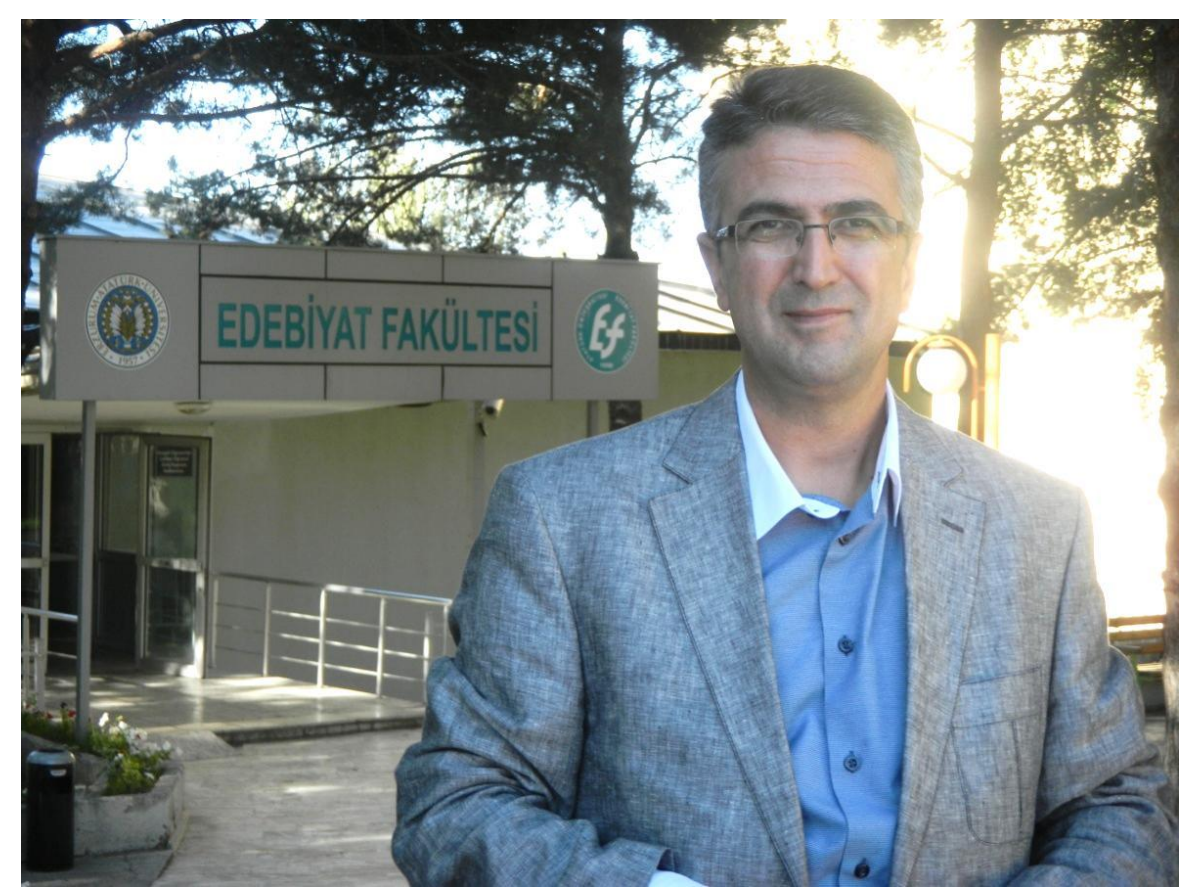

Fotoğraf 1: Prof. Dr. Kâmil AYDIN'ın görev yaptı̆̆l Atatürk Üniversitesi

Edebiyat Fakültesi önünde çekilmiş bir görüntüsü

Kâmil AYDIN, 1998 yılında East Anglia Üniversitesi’nin düzenlemiş olduğu Dil, Kültür ve Edebiyat Çalışmaları konulu programa katılarak "Dil-Kültür ve Edebiyat Öğretimi Uzmanlık Belgesi” alır.

2000 yılında doçent olan AYDIN, 2003 yılında ise kültürel çalışmalar kapsamında bir dizi araştırma yapmak üzere Amerika Birleşik Devletleri’nde bulunur.

Lisans ve lisansüstü seviyelerde Karşılaştırmalı Edebiyat, Çağdaş Amerikan Romanı, Çeviri Kuramı ve Tarihi, İngiliz Kültür Tarihi, Medya Araştırmaları... adlı dersleri veren; İngiliz Dili ve Edebiyatı, İngiliz Kültürü, Avrupa Birliği, Türk Kültürü, Kültürler Arası İlişkiler, Doğu-Batı Arasındaki Sosyal ve Kültürel İlişkiler... üzerine yapmış olduğu başarılı çalışmalarıyla tanınan Kâmil AYDIN, 2005 yılında profesör olur.

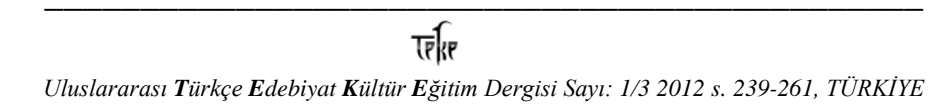


İngilizce ve Almanca bilen AYDIN, evli ve (Bilgenur ile Sencer adlarında) iki çocuk babasidır.

\section{Prof. Dr. Kâmil AYDIN'ın Eserleri:}

Kâmil AYDIN'ın, Karşılaştırmalı Edebiyat (Günümüz Postmodern Bağlamında Algılanışı), Entelektüel Yabancılar ve Ölümcül Kimlikler (Saul Bellow ve Sylvia Plath) ile Images of Turkey in Western Literature (Batı Edebiyatında Türkiye'nin İmajı) adlı üç kitabı bulunmaktadır. Bu makalede AYDIN'ın kitapları tanıtılmaya çalışılacaktır:

\subsection{Karşılaştırmalı Edebiyat (Günümüz Postmodern Bağlamında Algılanışı):}

Karşılaştırmalı Edebiyat Günümüz Postmodern Bağlamında Algılanışı (İstanbul, 1999, s. 192) adlı eser "Birey Yayıncılık" tarafından ilgililerin istifadesine sunulmuştur. Eserin düzenlemesi Gülseren Efilti; kapak tasarımı ise Sercan Arslan tarafından yapılmıştır.

Eserin 4. sayfasında Prof. Dr. Kâmil AYDIN'ın öz geçmişi yer almaktadır.

Eserin “Ön Söz”ünde ise, kürsüleşme yoluyla bilimsel yaşamına Avrupa'da XIX. yüzyılın ikinci yarısında başlayan karşılaştırmalı edebiyatın daha sonraları Amerika Birleşik Devletleri'nde ve diğer ülkelerde etkinlik kazanırken Türkiye'de birkaç bireysel girişimin dışında kuramsal ve akademik bir kimlik kazanamadığı ve isminden söz ettiremediği ifade edilmekte; mevcut eksiklikler ve çözüm yolları açıklanmaktadır.

AYDIN, ön sözde eserin içeriği hakkında da şunları kaydetmektedir:

Ülkemizde, bir vakıf üniversitesinde başlatılan programın dışında sistematik bir bölümleşme ve kürsüleşmeden yoksun karşılaştırmalı edebiyat kapsamında üretilen çalışmalara bakıldığında, yoğunluk ve ilginin terimin kuramsal, işlevsel veya yöntemsel boyutundan çok, doğrudan örnek araştırmalar üzerinde olduğu açıkça görülmektedir. Bir başka deyişle oldukça yeni bir çalışma olan karşılaştırmalı edebiyatın doğası ve evreleri pek de irdelenmemiştir. Dolayısıyla, bu boşluğu göz önünde bulundurarak yılların emek ve ürünü olan ve gerçekte İngilizce yazılması düşünülen bu çalışmanın Türk okuyucusuna ve araştırmacısına kazandırılmasına karar verilmiştir.

Ünlü karşılaştırmacı Peter Brooks'un karşılaştırmacı olmanın zorluğunu betimleyen düşüncelerine içtenlikle katılarak şunu da vurgulamak isterim ki; yurt dışı lisansüstü çalışmalarımı bu alanda tamamlamış olmama ve başta E. Said ve S. Bassnett olmak üzere bilinen karşılaştırmacılardan dersler ve seminerler dinlememe karşın, kendimi hiçbir zaman iyi bir karşılaştırmacı olarak görmedim. Dahası, bu mütevazı çalı̧̧manın çok iddialı olmadığını, aksine yalnızca konuyla ilgili küçük bir boşluğu dolduracak nitelikte olduğunu düşünmekteyim (Aydın, 1999: 5-6).

Yukarıda da belirtildiği üzere karşılaştırmalı edebiyatın günümüzdeki algılanış biçimi üzerinde yoğunlaşmayı amaçlayan Karşılaştırmalı Edebiyat (Günümüz Postmodern Bağlamında Algılanışı) adlı bu eserde, özellikle Anglo-Amerikan kaynaklardan yola çıkılarak yapılacaklar

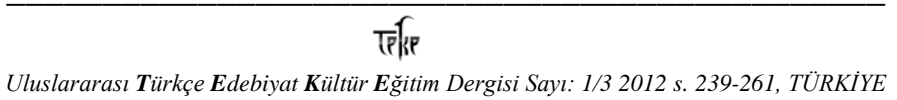


hususunda çok yönlü bir amaç güdülmüştür. Okuyucu, bir yandan Türkiye'de doğup gelişmeden yok olmaya yüz tutmuş bu yeni çalışma alanının tarihsel gelişimini ve geçirdiği evreleri tanıma olanăg bulurken diğer yandan da bu disiplinin, günümüzde postmodern bağlamda eriştiği uluslararasılık konumunu ve algılanış biçimini görmektedir.

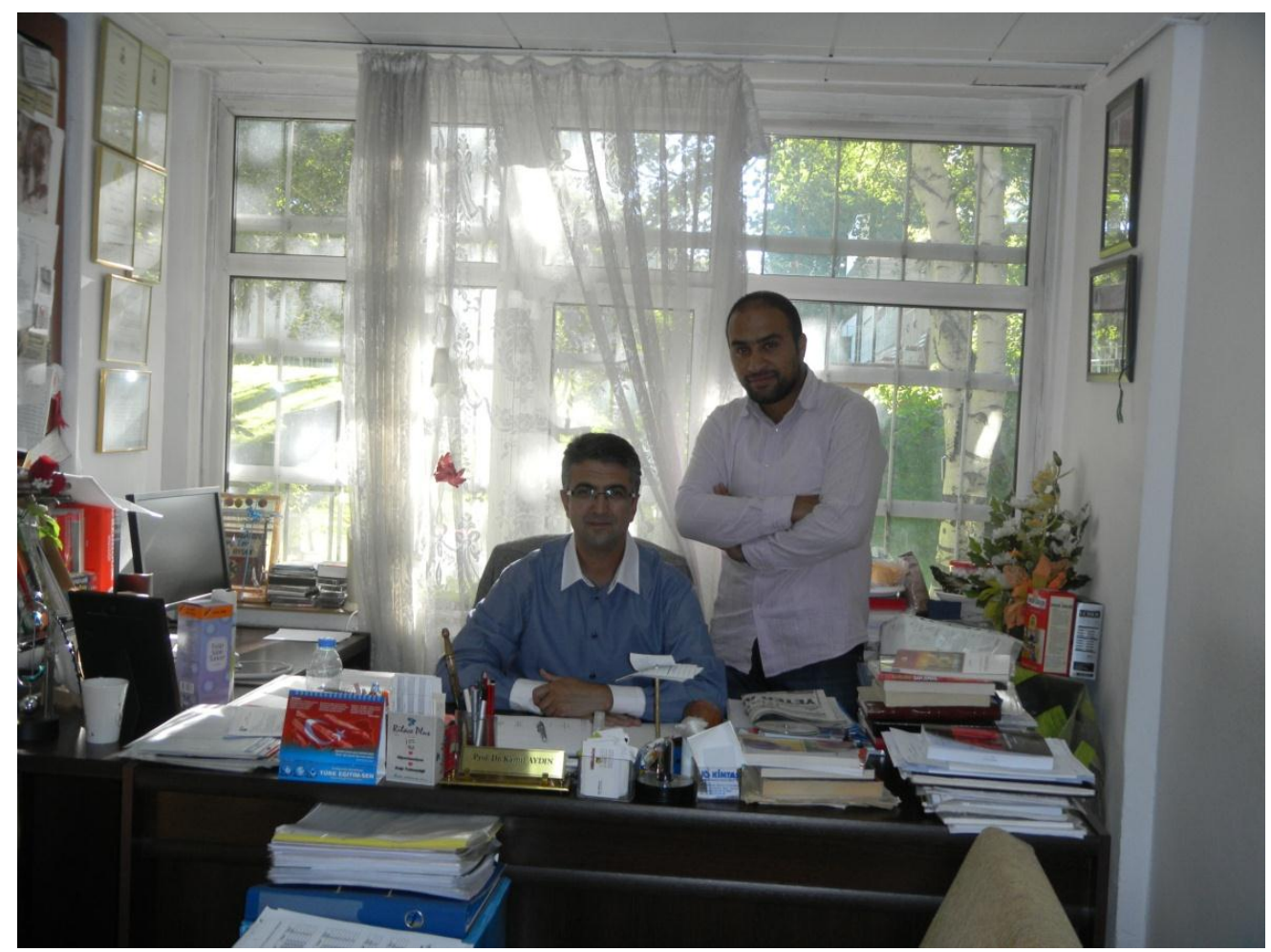

Fotoğraf 2: Okt. Siddlk BAKIR'ın Prof. Dr. Kâmil AYDIN'la birlikte çekilmiş bir görüntüsü

Karşılaştırmalı edebiyatın bütün yönleriyle ele alınıp incelendiği bu eseri ve bölümlerini şöyle değerlendirmek mümkündür:

“Giriş" (s. 9-17) bölümünde karşılaştırmalı edebiyatın ne olduğundan bahsedilmiş, karşılaştırmacıların terimin tanımı, içeriği ve işlevi noktasında yaşadıkları güçlükler ifade edilmiştir. Karşılaştırmalı edebiyatın biçim ve işlevinden bahseden yazar, Peter Brooks, Henry H. Remak gibi bazı karşılaştırmacıların tanım, sorun ve önerilerle ilgili birtakım düşüncelerine de yer vermiştir. Bunların yanı sıra, şimdiye kadar yapılmış olan uygulama örneklerinden yararlanılarak karşılaştırmanın nasıl yapılacağı ile karşılaştırma yöntemleri ve çeşitleri üzerinde durulacağı da belirtilmiştir.

“Birinci Bölüm” (s. 17-65) "Terimin Doğuşu ve Gelişimi, Uluslar Düzeyindeki Görünüm, Karşılaştırmalı Edebiyatın Üçüncü Dünyadaki Etkinliği ve Nedenleri, Karşılaştırmalı Edebiyat ve Karşılaştırmacı ile İlgili Düşünce ve Betimlemeler, Terimle İlgili Kavramlar veya Çalışma Alanları" adları altında beş alt bölüme ayrılarak karşılaştırmalı edebiyatın tarihsel 
süreci ve anlamı bütün yönleriyle ele alınmış, çözümlemeli ve geniş kapsamlı olarak irdelenmiştir.

“Terimin Doğuşu ve Gelişimi” (s. 17-26) bölümünde bugün bile gerek tanım ve içerik, gerekse uygulama yöntemleriyle ilgili olarak çeşitli tartışma ve söylentilerin yapıldığı karşılaştırmalı edebiyat teriminin kökenine inilerek, tarihsel gelişim süreci özetlenmiş, bazı ülke ve dillerdeki terimin farklı algılanış, biçimlenme ve kullanımına değinilmiştir. Matthew Arnold, Rene Wellek, Austin Warren, W. Von Goethe, Gürsel Aytaç, Benedetto Croce, Lane Coper gibi birçok kuramcı, eleştirmen ve bilim insanının düşüncelerinden hareketle karşılaştırmalı edebiyat hakkında okuyucuya geniş bir bakış açısı kazandırılmaya çalışılmıştır.

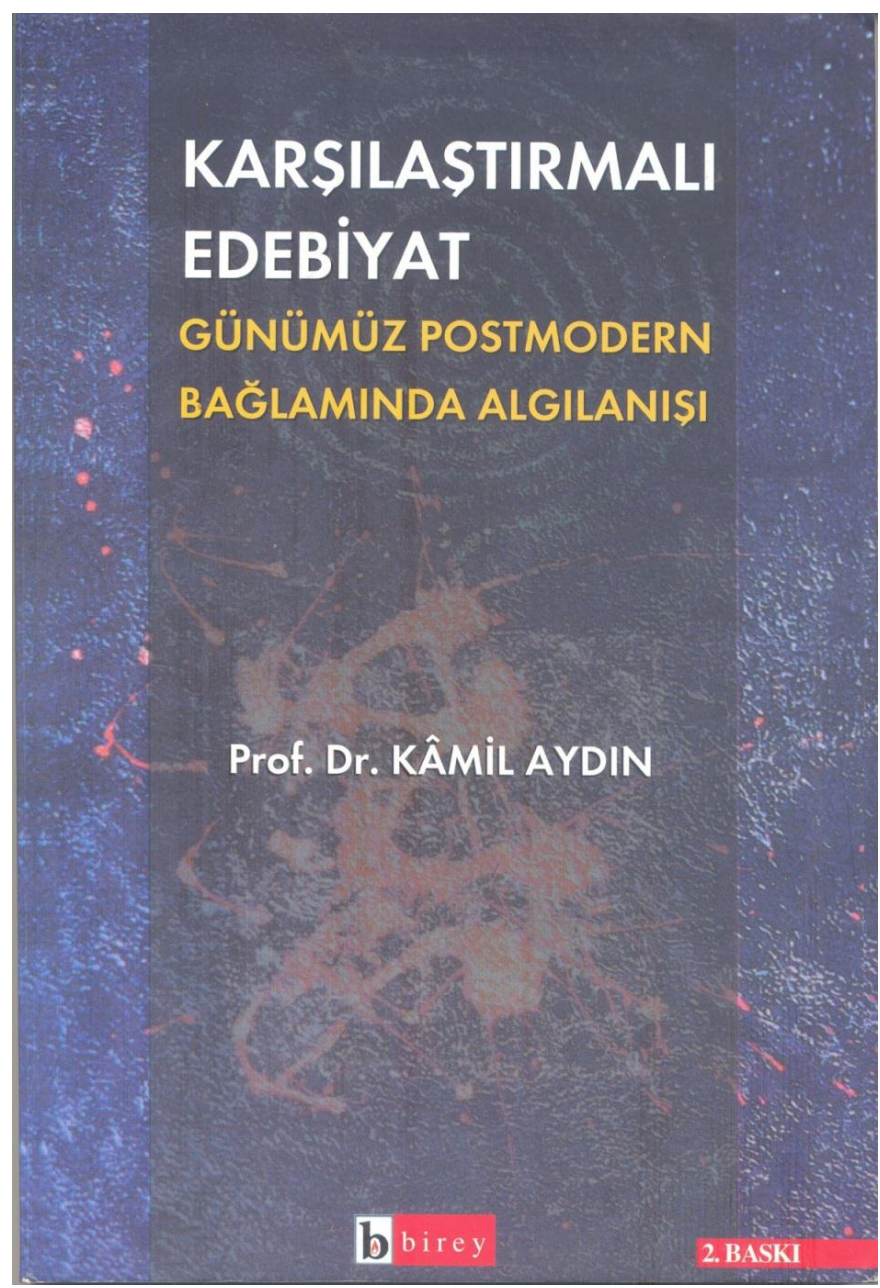

Fotoğraf 3: Karşılaştırmalı Edebiyat Günümüz Postmodern Bağlamında Algılanışı adlı kitabın kapak görüntüsü

"Uluslar Düzeyindeki Görünüm” (s. 26-49) adlı bölümde, karş1laştırmalı edebiyatın uluslar düzeyindeki tarihsel sürecine değinilmiş ve Fransa, Almanya, İngiltere, Amerika Birleşik Devletleri, İtalya, Rusya gibi devletler ile Doğu Avrupa ve diğer coğrafyalardaki 
ulusların bu disipline bakış açılarından bahsedilmiştir. Bu doğrultuda Fransa'nın ilk ve merkez olma özelliği üzerinde durulmuş, karşılaştırmalı edebiyat terimine ilk defa Fransız kaynaklarında rastlandığı örneklerle ifade edilmiştir. Bununla beraber karşılaştırmalı edebiyatın Almanya'da bir terim ya da bilim dalı olarak nasıl ortaya çıktığı, hangi süreçlerden geçtiği ve şu andaki algılanışına yer verilmiştir. Yine demokrasinin beşiği olarak bilinen İngiltere'de karşılaştırma ve edebiyat sözcüklerinin birlikte kullanımının hangi tarih ve olaya dayandığı ifade edilmiş, karşılaştırmalı edebiyatın İngiltere'de aslında 19. yüzyılın ortalarında gelişmeye başladığı belirtilmiştir. Bunun yanı sıra günümüzde hâlen daha karşılaştırmalı edebiyatın geçerliliğinden ve etkinliğinden bahsedilmesinde en büyük payın Amerika Birleşik Devletleri'nde olduğunu vurgulayan yazar bunda Amerika Birleşik Devletleri'nin farklı kültür ve etnik unsurlarını bir arada barındırmasının önemine dikkat çekmiştir. Çalışmanın devamında, kültür, sanat ve edebiyat bağlamında çoğu zaman Avrupa'ya 1ş1k tutan İtalya'nın karşılaştırmalı edebiyat konusunda isminden pek bahsedilmediği ifade edilmiş, hatta çoğu zaman özellikle Fransa tarafından dışlandığı dile getirilmiştir. Yine Rusya, Doğu Avrupa ve diğer uluslara bakıldığında, genel olarak tüm Doğu Avrupa ülkelerinde özellikle Rusya'da, karşılaştırmalı çalışmaların Marksizm'in etkisiyle daha çok sosyolojik temele dayalı olarak yürütüldüğü gözlemlenmiş ve altın çağını 20. yüzyılın yarılarında yaşadığı vurgulanmıştır.

“Karşıllaştırmalı Edebiyatın Üçüncü Dünya'daki Etkinliği ve Nedenleri” (s. 49-53) başlıklı bölümde, terimin Çin, Brezilya, Hindistan ve birçok üçüncü sınıf Asya ve Afrika ülkelerindeki varlığı, etkinliği, kullanım biçimi ve seyri üzerinde durulmuş, karşılaştırmalı edebiyatın kullanılacağı yere göre birtakım değişiklikler göstereceği belirtilmiştir. Bununla birlikte bu çalışma alanının Batı'da belirgin bir düşüş içinde olmasına rağmen birçok Asya, Afrika ve Doğu Avrupa ülkelerinde ise ivme kazanmasının dikkat çekici olduğu belirtilmiştir.

"Karşılaştırmalı Edebiyat ve Karşılaştırmacı ile İlgili Düşünce ve Betimlemeler” (s. 5356) bölümünde, Tieghem, H. H. Remak, Rousseau, Pichois, H. J. Schultz ve P. H. Rhein gibi birçok eleştirmen ve aydının karşılaştırmalı edebiyat ve karşılaştırmacı konularındaki benzer ve zıt fikirlerine değinilmiş; örneklerle ve açıklamalarla her ikisinin ne olması ya da olmaması gerektiği yönünde düşünceler açıklanmıştır.

"Terimle İlgili Kavramlar veya Çalışma Alanları" (s. 56-65) adlı bölümde yazar karşılaştırmalı edebiyatı, Evrensel Edebiyat, Uluslararası Edebiyat, Genel Edebiyat, Dünya Edebiyatı gibi birçok bölümle ilişkilendirmiştir. Bu ilişkilendirmede, Rene Wellek ve Austin Warren'in "Edebiyat Teorisi” de etkin rol oynamıştır ve buna da atıfta bulunulmuştur.

“İkinci Bölüm” (s. 65-115) "İlişki: Etki-Etkileşim ve Analoji, Akımlar, Ekoller ve Eğilimler, Yazım Türleri ve Biçimleri, Temalar, Motifler, Konular, Tipler, İmgeler ve 
Düşünceler” adları altında dört alt bölüme ayrılarak karşılaştırmalı edebiyatta yöntemsel sorun ve sınıflamalar üzerinde durulmuş, betimlemelerin daha anlaşılır ve açıklamalı olması için yapılması gerekenler örneklerle açıklanmıştır.

“İlişki: Etki-Etkileşim ve Analoji” (s. 69-82) adlı bölümde, etki, etkileşim ve analoji kavramlarının izahından, bunların ilişkilendirilmesinde dikkate alınması gereken ölçütlerden ve karşılaştırmalı edebiyatta bu üç unsurun ne denli önemli olduğundan bahsedilmiştir. Karşılaştırmacının herhangi bir değerlendirme yaparken edebiyatlar arasındaki ilişkiyi iyi çözümleyebilmesi, ilgili alanlarda yetkin olması ve etkileşimleri iyi çözümleyebilmesi gerektiği de bu bölümde ele alınan diğer önemli unsurlar arasında gösterilmiştir.

“Akımlar, Ekoller ve Eğilimler” (s. 82-89) bölümünde karşılaştırmalı edebiyatın konu olarak sadece kaynaklarla, isimlerle $v s$. ilgilenmediğinden aynı zamanda sanat, felsefe gibi edebî bilim ve eleştiri akımlarıyla da ilişkili olduğundan ve bunlarla da ilgilendiğinden bahsedilmiştir. Karşılaştırmalı edebiyat çalışmalarında özellikle yöntemsel açıdan Realizm ve Romantizmin, Realist ve Romantiklerin, akım ve eğilim çalışmalarının betimlenebilmesinde önemli bir yer tuttuğuna değinilmiştir.

"Yazım Türleri ve Biçimleri” (s. 89-98) adlı bölümde, yazım türleri ve biçimleriyle ilgili yapılan dolaylı ya da doğrudan çalışmaların nicelik ve niteliğinin karşılaştırmalı edebiyat, kuram ve eleştirisi için çok önemli olduğuna dikkat çekilmiştir. Yazım türü ve biçiminin kavramsal olarak eş anlamlı gibi görünmesine rağmen uygulamada farklı olduğundan bahsedilmiş özellikle anlamsal farklılıklara vurgu yapılmıştır.

“Temalar, Motifler, Konular, Tipler, İmgeler ve Düşünceler” (s. 98-115) bölümünde, herhangi bir eleştiri veya yorum çalışmasında, yapıtların düşünce, tez, tema, motif, tip, konu, olay örgüsü gibi birtakım belirgin unsurlarından söz etmek gerektiği belirtilmiş; bunlar açıklamalarıyla ve örneklendirerek ele alınmıştır. Birbirinden farklı gibi görünen bu ve benzeri kavram işaretlerinin farklı eserlerde ve farklı edebî dünyalarda birbirinin benzeri gibi ortaya çıktığı ifade edilmiştir.

“Üçüncü Bölüm” (s. 115-158) "Ulusçu ve Avrupamerkezci Eğilim (Fransız Ekolü), İkili Yöntem (etudes binaires), İkili Yöntemin 20. Yüzyıldaki Durumu, Liberal Algılanış Biçimi (Amerikan Ekolü) ve Kavramsal Yenilikler, Acla Toplantılarının Önemi, Karşılaştırmalı Edebiyatın Günümüz Postmodern Bağlamdaki Algılanışı, Kavramlar, Karşılaştırmalı Edebiyat ve Kültürel Çalışmalar" adları altında sekiz alt bölüme ayrılarak karşılaştırmacı edebiyatın algılanış biçimleri (ekoller) ve bugünü üzerinde durulmuş; edebiyat kuramı, eleştirisi ve tarihinin karşılaştırmalı edebiyata yansıması göz önünde bulundurularak edebiyat kuramının 
gelişim sürecinden, süreçte karşılaşılan durumlardan, etkileşimlerden detaylarıyla bahsedilmiştir.

"Ulusçu ve Avrupamerkezci Eğilim (Fransız Ekolü)” (s. 115-121) adlı bölümde, dönemin koşullarından soyutlanamayan sanat ve edebiyat ürünlerinin sağlıklı değerlendirilebilmesi ve karşılaştırmalı edebiyat algısının doğru betimlenebilmesi için Fransız (Avrupa) ve Amerikan (Avrupa dışı) ekollerinin irdelenmesi ve iyi analiz edilmesi gerektiği belirtilmiştir. Her iki ekol hakkında önemli isim ve eserlerden de yararlanılarak detaylı bilgiler verilmiş, tarihsel süreç göz önünde bulundurularak çeşitli örnekleme ve karşılaştırmalar yapılmıştır.

"İkili Yöntem (Etudes Binaires)" (s. 121-126) bölümünde, geçmişte olduğu gibi günümüzde de Fransa, Almanya ve İngiltere'nin üç süper güç olarak algılanışının karşılaştırmalı edebiyatın da ulusçuluk ideolojisinden bağımsız olarak gelişmemesine sebep olduğu belirtilmiştir. Buna bağlı olarak normalde karşılaştırmalı edebiyatın ruhuna aykırı olan, gelişen ve değişen yeni dünyada yaşam şansı bulamayan bu durumun günümüzde aşıldığı, konu ve içerik açısından olduğu gibi dilsel sınırların aşılmasının da söz konusu olduğu ifade edilmiştir. Bununla beraber bir karşılaştırmacının ikili bir çalışma yapabilmesi için iki dilde de yeterli olması gerektiği, edebiyatı öğrenilecek bir ülkenin, dilinin ve kültürünün iyi özümsenmesi gerektiği de örneklerle dikkat çekilen bir diğer ikili yöntem izahı olmuştur.

“İkili Yöntemin 20. Yüzyıldaki Durumu” (s. 126-131) adlı bölümde, iki farklı dilin gerekliliğini içeren Avrupamerkezci Fransız ekolünün etkinliğini 20. yüzyılda da gösterdiği belirtilmiştir. Özellikle Tieghem, Baldensperger, C. İ. Wrenn gibi bu akımın savunucularının görüşlerine yer verilerek, dilsel farklılıkların karşılaştırmaya engel teşkil ettiğini savunan bu isimlerin ve düşüncenin hiç de azımsanmayacak bir nüfuzunun olduğu ifade edilmiştir. Ancak, günümüzde, "karşılaştırmalı edebiyat konusunda yazılan birkaç klasik kitaptan birine sahip olan” diye nitelendirdiği Weisstein başta olmak üzere, R. Wellek, S. Bassnett gibi çağdaş karşılaştırma kuramcılarının bu tür sınırlandırmaları kabul etmedikleri, tüm bunların antic olduğu ve bu çalışma yönteminin postmodern dünyada kabul görmeyeceği üzerinde detaylarıyla durulmuştur.

"Liberal Algılanış Biçimi (Amerikan Ekolü) ve Kavramsal Yenilikler" (s. 131-136) bölümünde, Amerikan ekolünün tanımına, algılanış biçimine yer verilmiş; genel gelişim sürecinden bahsedilmiştir. Kuramsal olarak daha liberal ve demokratik yaklaşımla tutucu Fransız ekolüne tepki olarak betimlenen yeni ekolün elitizmi, Avrupamerkezciliği ve ataerkilliği reddettiği alanın uzman isimlerinin görüşleriyle de desteklenerek ifade edilmiştir. Buna rağmen

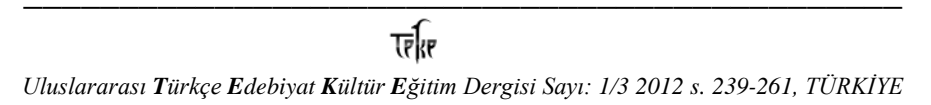


salt Avrupamerkezci bir ekolden bahsedilemediği gibi salt Amerikan ekolünden de bahsedilemeyeceği de gerekçeleriyle belirtilmiştir.

“Acla Toplantılarının Önemi” (s. 136-140) başlıklı bölümde, Amerikan Karşılaştırmalı Edebiyat Derneği (American Comparative ve Literature Association)'nin öneminden, geleneksel toplantılarından ve bu toplantılar sonucu hazırlanan raporların etkisinden bahsedilmiştir. Yine aynı bölümde, ilgili toplantıların zamanla nasıl farklılık gösterdiği, sonuçların geçmişten günümüze değişebildiği de sebepleriyle ele alınmış ve bu bağlamda çeşitli değerlendirmeler yapılmıştır.

“Karşılaştırmalı Edebiyatın Günümüz Postmodern Bağlamdaki Algılanışı” (s. 140-143) adlı bölümde, İkinci Dünya Savaşı sonrası hâlen daha etkinliğini sürdüren Avrupamerkezci (Fransız) eğilimin, Amerikan ekolü ve sonrasındaki birtakım evrensel değerlerin gündeme gelmesiyle kan kaybetmiş olduğundan bahsedilmiş, Batı Edebiyatları adıyla anılan bölümlerin artık farklı seçenekler sunduklarına dikkat çekilmiştir. Yine dönemin üniversiteli aydınlarının, entelektüellerinin edebiyat kuramları, gösterge bilimi, medya araştırmaları ve kültürel çalışmalar gibi konulara yönelmelerinin eski, tutucu bazı karşılaştırmacıların alandan uzaklaşmasına neden olduğu ifade edilmiştir. Bununla beraber benzer durumun Batı dünyası dışında gözlenemediği aksine evrensel karşılaştırma değerlerine bağlı olmadıkları, ulusal edebî çalışma düşüncesine bağlı oldukları gözler önüne serilmeye çalışılmıştır.

“Kavramlar” (s. 143-150) bölümünde, 20. yüzyılın sonundaki hızlı ve güçlü teknolojik ve bilimsel gelişmelerin sınırları kaldırdığı, dünyayı küçülttüğü gibi kültür, sanat, edebiyat ve benzeri alanlarda da varlığını hissettirdiği düşüncesinden hareketle tüm bunların karşılaştırmalı edebiyata da etki ettiği belirtilmiştir. Bunun da yeni kavramların ortaya çıkmasına, kullanılmasına ve tartışılmasına yol açtığı muhakkaktır. Bu koşullar altında karşılaştırmacıların sınırlarını gözden geçirdiğini ve buna bir anlamda zorunlu olduklarını belirten yazar, küreselleşme, demokratikleşme, dekolonizasyon, çok kültürcülük ve dilcilik, popular kültür ve feminizm gibi birtakım postmodern kavramları incelemiş ve kavramlar üzerinden sebep-sonuç ilişkileri kurarak bir süreç yorumlamasına gitmiştir.

"Karşılaştırmalı Edebiyat ve Kültürel Çalışmalar" (s. 150-158) başlıklı bölümde, bazı eleştirmenlerin sanat ve edebiyat doğrultusunda, demokratikleşme ve küreselleşme evrensel süreçlerinin doğal sonucu olarak karşılaştırmalı edebiyatın kendi kimliğinden ve doğasından uzaklaştığı fikrine yer verilirken, tam aksini iddia eden eleştirmenlerin, karşılaştırmalı edebiyatın kültürel çalışmalar gibi alanlarla iş birliği yapması gerektiği fikrine de yer verilmiştir. Bununla beraber her iki düşünce farklılığının temelinde dil ve içerik kavramlarının önemli yer tuttuğu vurgulanmış ancak karşılaştırmalı edebiyatla kültürel çalışmalar arasında

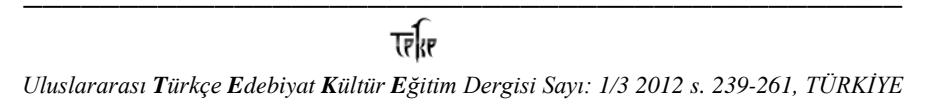

International Journal of Turkish Literature Culture Education Volume 1/3 2012 p. 239-261, TURKEY 
mukayesenin yerine birlikteliğin, yeniden adlandırılmanın ve her ikisinin de varlığını devam ettirmesinin önemli olduğuna dikkat çekilmek istenmiştir.

"Sonuç: Nereden Nereye" (s. 158-165) bölümünde, geçirdiği evreler dikkate alınarak, karşılaştırmalı edebiyatın, tarihsel dönemlerin ekonomik, siyasal ve sosyo-kültürel koşullarına uygun olarak bir evrimleşme yaşadığı, bununla birlikte karşılaştırmalı edebiyatın nerede başladığı bilinmesine rağmen nereye gideceğinin belirsiz olduğuna değinilmiştir. Hemen her konuda olduğu gibi bu konuda da ciddi fikir ayrılıklarına düşen aydınların karşılaştırmalı edebiyatın tanımı, yaşam alanı ve süresi, ilişkileri ve benzeri konulardaki düşüncelerine yer verilmiş, an itibarıyla karmaşık bir dönemden geçildiği belirtilmiştir. Özellikle 1990'larda başlayan yeni dönemle birlikte karşılaştırmalı edebiyatın kendine yeni isimler bulması gerektiği iddia edilmiştir.

“Tarihsel Sürecinde Karşılaştırmalı Edebiyat Kuram ve Uygulamasına Katkıda Bulunan Karşılaştırmacılar" (s.165-181) adlı bölümde karşılaştırmalı edebiyat kuramları, kuramcıları ve onların genel düşünceleri kısaca ele alınmış, bunların başarılı, titiz bir tasnifi yapılmış ve bunlar ilgililerin faydalanabilmesi düşüncesiyle özet şeklinde sunulmuştur.

Bu bölümde Alman şair ve yazar Goethe, Fransa'nın gerçek anlamdaki ilk kozmopolit eleştirmeni olduğu düşünülen Philaréte Euphémon Chasles ve İngiliz Profesörü karşılaştırmalı edebiyatçı Charles Chauncey Shackford'un alanla ilgili ne kadar yetkin isimler olduğundan ve onların çalışmalarından söz edilmektedir. Çok dilli bölgenin çok dilli çocuğu olan ünlü kuramcı Hugo Meltz de Lomnitz ile aldığı eğitim sonucu karşılaştırmalı edebiyatçı olan Alman Max Koch'un karşılaştırmalı edebiyat hakkındaki düşüncelerinin, bu alandaki yeri ve öneminin belirtildiği kısımlar da bu bölümde yer almaktadır. Karşılaştırmalı edebiyat kuramı, yöntemi ve ilkelerini kullanan ilk Fransız eleştirmeni olan Joseph Texte ile Latin araştırmaları Profesörü olan ve karşılaştırmalı edebiyata olan katkılarından dolayı Amerika'da etkin bir konuma gelen Charles M. Gayley'e de bu bölümde yer verilmektedir.

22 yaşında (1883) Kansas Üniversitesi’ne İngiliz Edebiyatı Profesörü olarak atanan Arthur Richmond Marsh'a ve onun ilginç yaşam öyküsü ile alandaki başarılı çalışmalarına, Almanca konuşan bir baba ve Fransızca konuşan bir annenin çocuğu olarak dünyaya gelen, hukuk eğitimi aldıktan sonra edebiyata yönelerek karşılaştırmalı edebiyatın en önemli isimlerinden biri olmayı başaran Louis Paul Betz'e de detay ve örneklerle bu bölümde yer verilmektedir.

Edebî yaşamının otuz yılı boyunca Fransız eleştirisi, draması ve lirik şiiri ile bunların tarihi üzerine her yıl en az bir kitap yazarak, akademik etkinliğini sürdürmüş olan Fransız 
Akademisi üyesi Ferdinand Brunetiere de karşılaştırmalı edebiyat hakkındaki düşünceleriyle bu bölümde yer almaktadır. İrlandalı bir avukat olan Hutcheson Macauly Posnett ile biyografik ve eleştirel ürünlerinin çokluğuyla tanınan eleştirmen George E. Woodberry'den de bu bölümde bahsedilmiştir.

Bir toprak ağasının oğlu olan Benedetto Croce ve onun ilginç yaşam öyküsü, etkin ve zengin siyasal yaşam tarzı da eser de kendine yer bulmuştur. Ömür boyu senatörlük elde etmiş olan Croce, demokratik İtalya'nın kurulmasına katılan ilk İtalyanlar arasında saygın yerini almıştır. Edebiyat ve estetiğe yaklaşımı yüzlerce kitap ve yazıda görülebilmektedir. Ayrıca bu bölümde Filistinli Hristiyan bir ailenin çocuğu olarak 1935'te Kudüs'te dünyaya gelen Edward W. Said'in yaşam öyküsü anlatılmış, edebiyat eleştirisi ve kuramları hakkındaki düşünceleri dile getirilmiş ve Orientalism (1978) eseri tanıtılmıştır.

$\mathrm{Bu}$ bölümün sonunda ise yazarın bu alana yönelmesinde önemli pay sahibi olan ve karşılaştırmalı edebiyatın son dönem en önemli isimlerinden biri olarak gösterilen Susan Bassnett tanıtılmakta; Bassnett'in 1970'lerden beri dünyanın çeşitli üniversitelerinde yaptığ çalışmaları ilgililerin dikkatine sunulmaktadır.

“Karş1laştırmalı Çalışma Örnekleri” (s. 190-192) bölümünde ise karşılaştırmalı edebiyat çalışmaları yapanlar ve onların eserlerine şu şekilde yer verilmiştir:

Ann Gelder, "Wandering in Exile: Byron and Pushkin". Antoniette Burton, "Rules of Thumb: British History and 'Imperial Culture' in nineteenth-and twentieth-Century Britain".

Arnold Goldman, "A Remnant to Escape: The American Writer and the Minority Group".

Bruce Donahue, "Viewing the West from the East: Solzhenitsyn, Milosz, and Kundera”.

Burton R. Pollis, "Philosophical and Literary Sources of Frankenstein".

Calvin S. Braun, "The Relations Between Music and Literature as a Field of Study".

D. L. Fanger, "Romanticism and Comparative Literature". Drummond Bone, "Byron at Cambridge: The New Hermeticism".

Drummond Bone, "First Look at Exile: Byron's Art in 1816".

Drummond Bone, "Shelley, Wordsworth, and Byron: The Detail of Nature".

E. M. And S. B. Puknat, "Edith Wharton and Gottfried Keller".

Frank J. Warnke, “The Comparatist's Canon: Some Observations”.

Frederic Garber, "Beckford, Delacroix and Byronic Orientalism".

Frederick J. Hoffman, “The Religious Crisis in Modern Literature”.

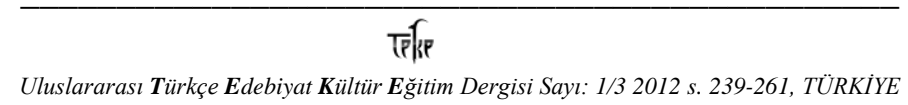

International Journal of Turkish Literature Culture Education Volume 1/3 2012 p. 239-261, TURKEY 
Garland Cannon, "Foundations of Orientel and Comparative Studies: The Correspondence of Sir William Jones".

Georg M., "Gugelberger, Blake, Neruda, NgugiwaThiango: Issues in Third World Literature".

Hans Galinsky, "Literary Criticism in Literary History: A Comparative View of the 'Uses of the Past' in Recent American and European Histories of American Literature".

Harry Lewis, "Literature and Cultural Idendity".

Irwing Ribner, "Marlowe and Machiavelli".

J. M. Rignell, “The Historical Double: Waverley Sylvia's Lovers, The TrumpetMajor".

J. P. Stern, "Literature and Ideology".

Johan Wrede, "Reading as Experience: on the Aesthetics of Literary Interpretation and Criticism".

Josie P. Campbell, "To Sing the Song, To Tell the Tale: A Study of Toni Morrison and Simone Schwarz-Bart".

Leonardo Olschki, "Mohemmedan Eschatology and Dante's Other World”.

Lisa Lowe, "The Orient as Woman in Flaubert's Salammbô and Voyage en Orient".

M. A. Manzalaoui, “Tragic Ends of Lovers: Medieval Islam and the Latin West”.

Marjorie Perloff, "Yeats and Goethe".

Martin M. Winkler, "Classical Mythology and the Western Films".

Maurice. J. Bennett, "The Dedective Fietion of Poe and Borges”.

Michel Benamou, "Wallace Stevens: Some Relations Between Poetry and Painting".

Mick Kaye, "Thinking Postmodernisms on T. Docherty After Theory, and F. Jameson, Postmodernism”.

Newton Arwin, "Individualism and the American Writer".

Paul Coates, "Cinema, Symbolism and the Gesamtkunstwerk".

Paula M. Clifford, "The American Novel and the French Nouveau Roman: Some Linguistic and Stylistic Comparisons".

Percy G. Adams, "The Discovery of America and European Renaissance Literature",

René Wellek, "Benedetto Croce: Literary Critic and Historian”.

René Wellek, “The Concept of 'Romanticism' in Literary History”.

Richard Maxwell, "City Life and the Novel: Hugo, Airsworth Dickens".

Robert Shackleton, "Montesquieu and Machiavelli: A Reappraisal".

Roxandra V. Antoniadis, "Faulkner and Balzac: The Poetic Wei SalihaPaker, "Hamlet in Turkey".

Shunsuke Kamei, "The Kiss and Japanese Culture After World War II".

T. M. Ritchie, "European Literary Exiles".

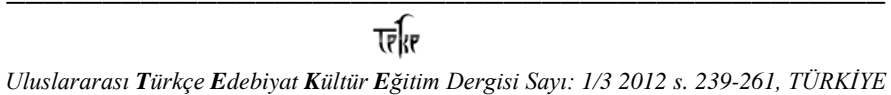

International Journal of Turkish Literature Culture Education Volume 1/3 2012 p. 239-261, TURKEY 
Thomas R. Steiner, "Precursors to Dryden: English and French Theories of Translation in the Seventeenth Century".

Wallace Martin, "The Hermeneutic Circle and the Art Interpretation".

William Moebius, "Lines in the Sand: Comparative Literature and the National Literature Departments".

\subsection{Entelektüel Yabancılar ve Ölümcül Kimlikler (Saul Bellow ve Sylvia Plath):}

Entelektüel Yabancllar ve Ölümcül Kimlikler Saul Bellow ve Sylvia Plath (Erzurum, 2005, 165 s.) adlı bu çalışma Eser Ofset Matbaacılık tarafından yayımlanmıştır. Eserin kapak tasarımı Selami Aydın tarafından yapılmıştır.

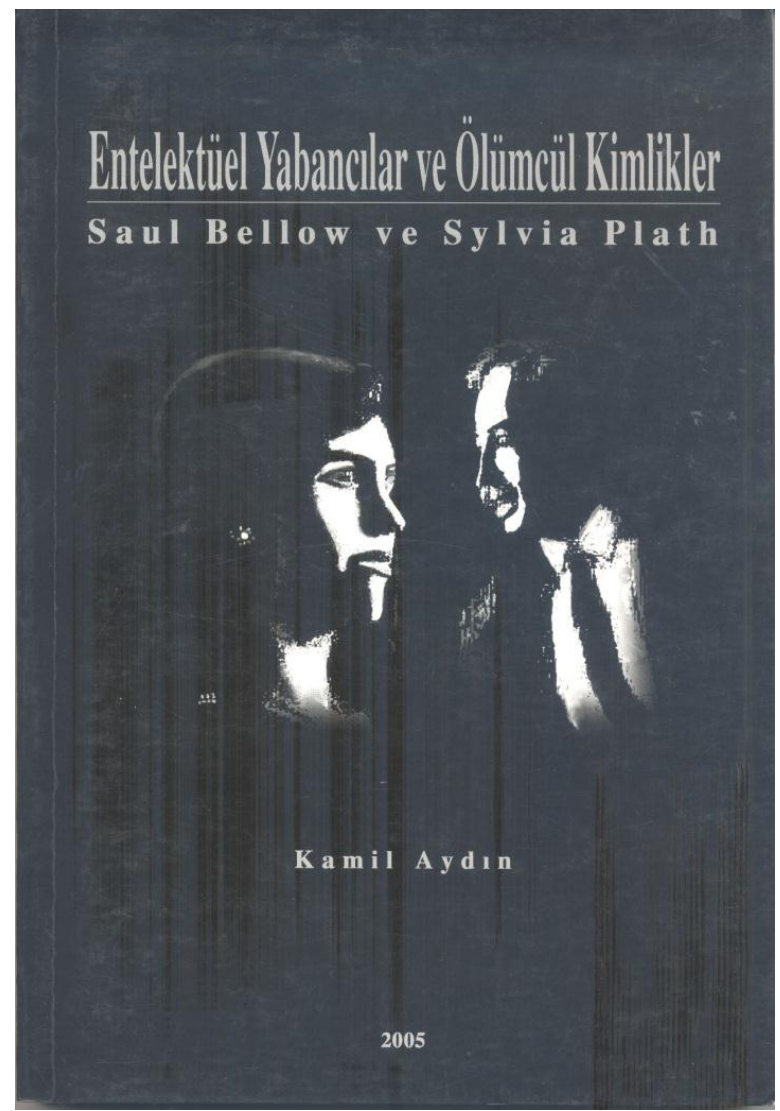

Fotoğraf 4: Entelektüel Yabancllar ve Ölümcül Kimlikler Saul Bellow ve Sylvia Plath adlı kitabın kapak görüntüsü

Entelektüel, aydın, toplumsal sorumluluk, kimlik, modernizm, mazoşizm, yalnızlık, ölüm gibi insan ve yaşamla ilgili daha birçok kavramın bütün yönleriyle ele alınıp, örneklerle ortaya konduğu, Sirça Fanus ve Nefret adlı yapıtlarla desteklenen eseri ve bölümlerini şöyle değerlendirmek mümkündür:

Eser, yazarın Sylvia Plath ve Saul Bellow isimleriyle nerede, ne zaman, nasıl karşılaştığını belirttiği, konuya olan ilgisinin ve kitap yazma fikrinin nereden geldiğini 
açıkladığı; ayrıca yapıtın ortaya konmasına katkı sağlayan, esere bir anlamda can veren ilgililere teşekkür ettiği "Sunuş" bölümüyle başlamaktadır.

"Giriş" (s. 1-14) bölümünde yazar, Sylvia Plath ve Saul Bellow’un, yaşadıkları dönemin siyasal, ekonomik, toplumsal ve kültürel olaylarından yapısal ve tematik olarak hızla etkilenen edebiyat dünyasına özgün eserler vererek önemli katkı sağladıklarını belirtmektedir.

On yıldan daha az bir sürede 170'in üzerinde şiir, birçok deneme ve öykü yazan, aynı zamanda en ünlü Amerikalı kadın romancılardan biri olan Sylvia Plath'ın biyografisiyle devam eden bu bölümde S. Plath'ın akademik ve sanatsal yeteneğinden kronolojik olarak bahsedilmektedir. Bununla birlikte yaşadığı iç çekişmelerin, psikolojik durumların öyküsü olan Sırça Fanus (The Bell Jar)'un nasıl ortaya çıktığı, ne kadar sürede ve hangi şartlarda tamamlandığı bu bölümde dikkate sunulan diğer hususlar olarak görülmektedir.

Roman, yazarın hayatından önemli izler taşımakta ve somut resimler barındırmaktadır. Bostonlu genç bir kızın ikilemlerinin, bunalımlarının, çöküntü, intihar ve iyileşme gibi psikososyal durumlarının incelendiği eser S. Plath'ın tek romanıdır ve bu romanda başkahraman Esther Greenwood'un iç dünyasındaki çatışma anlatılmaktadır.

Bölümün devamında, tanıyanların tam bir büyük kent entelektüeli olarak betimledikleri, yaşamı boyunca birçok ödül ve burs alan; ancak asıl ününü 1976'da Nobel Edebiyat Ödülünü alan ilk Amerikalı yazar olarak elde eden Saul Bellow'un hayat hikâyesine yer verilmektedir. Yine bu bölümde birçok Amerikan kuruluşundan ödül alan, önde gelen birçok dergi ve yayına yazı gönderen ve bir o kadar öykü, inceleme, romanla da ünlenen S. Bellow'un Nefret (Herzog) romanı, konu, kişi ve mekân gibi hususlar açısından değerlendirilmektedir.

Nefret, üniversitede bir profesörün iç hesaplaşmasının, çevresini sorgulamasının ve kendi kurtuluş mücadelesinin romanı olarak betimlenmektedir. Özellikle ötekileşme ve yabancılaşma düşüncelerinin doğrudan sonucu ve kaçınılmaz sığınağı olan mazoşizmin eserde çok belirgin olduğuna dikkat çekilirken bu durumun zaman zaman intihara kadar gidebildiği belirtilmekte ve tehlikenin boyutları göz önüne serilmektedir.

Çoğu zaman entelektüel bir görev ve sorumluluk içerisinde, kendilerini çeşitli siyasal, toplumsal ve psikolojik sorunların içinde bulan gizemli bireylerin romanlarını yazmayı tercih eden S. Plath ve S. Bellow'un bu tarz bir seçim yapmalarında onların yalnızca insancıl düşüncelerinin değil, aynı zamanda toplumsal sorumluluklarının da etkili olduğu ifade edilmektedir.

Konuyla ilgili olarak yazar şunları kaydetmektedir: 
Bu çalışmada öncelikli yoğunluk, S. Plath ve S. Bellow'da bireyin toplum içerisinde yüz yüze geldiği sorunsallık üzerine olacaktır. Bunu yaparken yazarlara ait örnek kaynaklar olarak Sırça Fanus ve Herzog irdelenecektir. Çünkü her iki romanın kahramanları veya 'bireyleri' gerçek ortak özellikler sunmakta ve hemen hemen benzer sorunlarla karşılaşmaktadırlar. Bu ortak özeliklere somut bir örnek olarak, her ikisinin de dış dünya ile yakın bir ilişki içerisinde bulunamamalarından kaynaklanan psikolojik anlamdaki yalnızlık ve soyutlanmışlık temaları gösterilebilir.

Adı geçen iki romancının tercih edilmesinde etkin olan diğer bir neden; onlar tarafından yazılan her iki yapıtın da otobiyografik özellikler taşımasıdır. Herzog'da daha az olmakla birlikte durum özellikle Esther Grenwood tiplemesiyle Sirça Fanus'ta daha belirgindir. Tam anlamıyla birleştikleri noktalar da vardır. Örneğin romanların kahramanları sanata ve entelektüel özelliklere sahiptirler ve bu özellikleri romanların işleniş süreci içerisinde çeşitli biçimlerde sergilenmektedir (Aydın, 1999: 8).

Yazara göre her iki romancı da kendi yaşam öyküleri ve deneyimleri 1şı̆̆ında bireyin sorunları üzerinde durmaya çalışmaktadır. S. Plath ve S. Bellow'un romanlarına ilişkin önemli görülen bir diğer noktanın dil ve anlatım tekniklerini kullanmadaki ustalık olduğunu belirten AYDIN, her iki yazarın betimleme gücünün de başarıya katkı sağladığını düşünmekte ve bunu örneklerle ilgililerin dikkatine sunmaktadır.

Tüm bu söylenenlerden hareketle yazar, çalışmanın ilk bakışta birbirinden bağımsız gibi görünen bölümlerinin ilkinde, Plath ve Bellow’un sanatçı ve entelektüel kimliklerinin mercek altına alınacağını; fakat bunu sağlıklı bir zemine oturtmak için öncesinde entelektüel kavramının çeşitli yönleriyle irdeleneceğini belirtmektedir. İkinci bölümde, sorumluluk duygusu taşıyan birer sanatçı ve entelektüel olarak yazarların karşılaştıkları sorunlara zemin hazırlayan dönemlerine siyasal ve toplumsal açıdan göz atılacağını vurgulamaktadır. Üçüncü bölümde ise, özellikle 1950'lerde ve 1960'larda varlığını yoğun bir biçimde hissettiren, hatta birçok toplumsal tepki ve gösterilere neden olan erkek-merkezli toplumsal yapı ve azınlık sorununun ele alınacağını ifade eden yazar bunların tamamına somut örnek olarak da Sylvia Plath'ın Sırça Fanus'unu, Saul Bellow'un da Nefret adlı eserlerini kullanmaktadır.

“Toplumsal Görev ve Sorumluluk Işı̆̆ında Entelektüel (Aydın) Kavramı” (s. 14-30) adlı bölümde yazar; düşünce, sanat ve yazının tarihsel sürecine göz atarak düşünür, sanatçı ve yazarların toplumu bilgilendirme, bilinçlendirme veya yönlendirme gibi görevlerinin olduğunu belirterek entelektüel kavramının, etimolojik durumunu, tarihsel ve toplumsal gelişimini irdelemektedir. Geleneksel anlamı içinde bilgili, değerlendirme ve eleştiri gücü yüksek, topluma öncülük etme misyonu yüklenmiş entelektüellerin farklı çağlardaki ve farklı kişilerdeki tanımları, özellikleri yine bölümde ele alınan hususlardan birkaçını oluşturmaktadır. Yine bu bölümde şimdiye kadar yüzeysel algılanış biçimleri ve geçirdiği evreleri sunulan aydın veya entelektüel kavramının, çeşitli düşünür ve sanatçılar tarafından nasıl yorumlandığı belirtilmekte;

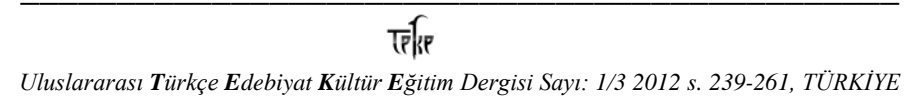

International Journal of Turkish Literature Culture Education Volume 1/3 2012 p. 239-261, TURKEY 
yer yer onlara söz verilerek aydının kim olduğu ya da olmadığı, toplumsal bir ayrıcalığa sahip olup olmadığı, marjinal, ideal, normal $v b$. kavramlarla bağdaşıp bağdaşmadığı gibi sorulara cevaplar aranmaktadır. Gerek soru-cevaplardan gerekse sunulan örneklerden de anlaşıldığ üzere, profesyonel işi ne olursa olsun, kimi zaman filozof, kimi zaman din adamı, çoğu zaman da sanatçı, yazar, şair ve eleştirmen olan entelektüelin görev ve sorumlulukları ile ön plana çıktığı dikkate sunulmaktadır.

“Entelektüel Kimlikler” (s. 30-41) adlı bölümde, S. Bellow’un varoluşçu söylemin etkisinde kalarak her bireyin farklı varoluşunun söz konusu olduğunu ve mutlak varlığın da kısmen bir aldatmaca olduğunu belirttiği ifade edilmekte; onun romanlarının entelektüel bağlamı üzerinde durulmaktadır. Eserleri, kişileri, olayları ve düşünceleri yine eserlerinden örneklerle ve çeşitli eleştirmenlerin görüşleriyle ele alınan diğer unsurlar olarak karşımıza çıkmaktadır.

Bu bölümde ayrıca üslubu ve başarısı, kısmen sorunlu yaşamı ve entelektüel geçmişiyle açıklanabilen S. Plath'ın büyük bir şair olduğu kadar birtakım garip rastlantılar sonucu nasıl büyük bir romancı da olduğu açıklanmaktadır. Şairliğinin yanı sıra entelektüel sorumluluğun da bilincinde olduğu belirtilen S. Plath'ın hem Amerika hem de Avrupa'da yaşamış ve çalışmış olması sebebiyle Amerikalı ve Avrupalı çağdaşlarını okuduğunu ve onlardan etkilendiğini ifade ettiği dile getirilmiştir. Tüm bu düşüncelerin, kazanım ve deneyimlerin, yaşanan üzüntü, ikilem ve çelişkilerin S. Plat'ın yapıtlarına yansıdığını ifade eden yazar, bunu eserlerden örneklerle ve saygın eleştirmen görüşleriyle de desteklemektedir.

“1950 ve 1960’ların Toplumsal ve Siyasal Görünümü” (s. 41-51) adlı bölümde edebiyat ve eleştirinin tarihî sürecine bakıldığında, her dönem sanat ve edebiyatının o dönemin sosyal, siyasal ve kültürel durumlarından etkilendiği vurgusuyla sanat ve edebiyatın toplumsal boyutuna dikkat çekilmektedir. S. Plath ve S. Bellow'un daha iyi özümsenmesi ve anlaşılması için Sırça Fanus ve Nefret' in bu açılardan ele alınması gerektiğini belirten yazar bu düşünceden hareketle 1950'li ve 1960'lı yılları çok yönlü bir şekilde inceleyip eserler arasında da ilişki kurmaya çalışmaktadır. Kore Savaşı, McCarthyism, Macar Ayaklanması, insanların birbirlerine insanlık dış1 uygulamalar yaptığı bir toplum ve benzeri birçok olay, Plath'ın karşı çıktığı ve Strça Fanus'ta derin izleri görülen olayların başında gelmektedir. Buna benzer olarak Herzog (Nefret) başta olmak üzere Bellow ve eserleri hakkında yazar şunları söylemektedir:

Gerçekte bütün bu olaylar ve sorunsallık, yazınsal üretim için çok iyi bir malzeme ve zemin hazırlamaktaydı ve Bellow da romancı olarak bütün bunlardan oldukça etkilenmiş ve yararlanmıştı. Yani, romancının işlevi zamanını yansıtmaksa S. Bellow sanatın gereğini yerine getirmek için elinden geleni yapmıştır. Belirgin birçok grubun insanın yok edilişine ve bireyselliğin ortadan kaldırılmasına aynı

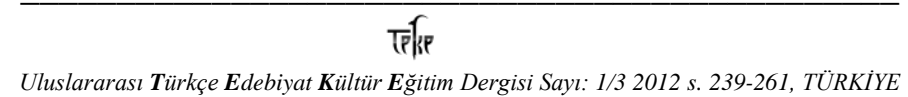

International Journal of Turkish Literature Culture Education Volume 1/3 2012 p. 239-261, TURKEY 
yaklaşımı sunarken, Bellow bütün yapıtlarında bireyin dış dünya ile ilişkisindeki sorunları ele almıştır. Dahası, onun karakterleri toplumsal ve ekonomik güvensizliğin baskısı altındaki modern Amerika'nın katı ve acımasız görünümünü, çevrelediği dünyayı tanımaktadır. Bellow için yazarın dikkatini yönlendirmesi gereken asıl konu insanın durumudur; çünkü sanatın belirleyici ve biçimlendirici malzemesi insanlığın düşleri ve deneyimleri olmuştur (Aydın, 2005: 48).

“Irk ve Cinsiyet Ayrımı” (s. 51-68) başlıklı bölümde, 1950’lerin ve 1960'ların tutucu, baskıcı sosyal ve siyasal ortamında ırk, renk, cinsiyet, ikincil, azınlık gibi kavramlar ele alınmakta, dönemin Avrupa ve Amerika toplumları, aydınları ve olayları göz önüne koyulmaktadır. S. Plath'ın cinsiyetinden dolayı (bayan olduğu için), S. Bellow'un da dinsel ve kültürel geçmişinden dolayı (Yahudi kökenli ve bir göçmen ailenin çocuğu olduğu için) birçok eleştirmen tarafından ikincil ya da azınlık olarak değerlendirildiği iddia edilmekte bunun sebebi olarak da dönemin etkin kültürel ve sosyo-politik söylemi gösterilmektedir. Yine bu bölümde her iki eser aşk, cinsellik, evlilik, tabular, dinsel ve ırksal ön yargılar, dinsel, dilsel ve kültürel değerler gibi birçok noktadan ele alınmış ve tüm bu kavramlar, çatışmalar, çelişkiler eserlerden örneklerle ve eleştirmenlerin görüşleriyle desteklenerek sunulmuştur.

“Toplum ve Çevresel Koşullar: Modern Kent Yaşamı” (s. 68-79) adlı bölümde, modern toplumların sosyolojik incelemelerinden söz ederken, aynı zamanda kentsel yaşama da değinmek gerektiği düşüncesinden hareketle Amerika ve Avrupa'daki modernleşme, kentleşme, sınıfsal bakış, tarım ve sanayi toplumları, teknolojik kolaylıklar ve bunların günlük yaşamdaki etkileri gibi birçok hususun yazın hayatında da önemli bir yer tuttuğuna değinilmekte ve tüm bu kavramsal tarihsel süreçler dikkate alınarak değerlendirilmektedir. Yazar, yukarıda belirtilen unsurları gerek Plath'ın Strça Fanus'undan gerekse Bellow'un Nefret'inden örnek cümleler vererek ve detaylı çözümlemeler yaparak somutlaştırmaktadır. Dış dünyanın ilgisizliği ve düşmanca tavrı, toplumdaki yapaylık, iki yüzlülük ve kalabalık, kargaşa ortamları, umutsuzluk, yozlaşma ve mutsuzluk gibi her iki eserin ve yazarın başlıca konularını oluşturduğu bu duygu ve kavramlar Aydın'a göre toplum ve çevresel koşullar bağlamında dönemin modern kent yaşamını da anlatmakta ve 1950'lerin, 1960'ların Avrupa ve Amerika'sını da başarılı bir şekilde betimlemektedir. İki roman arasındaki en belirgin karşılaştırma noktasının, Sırça Fanus'ta 1950'li, Nefret'te ise 1960'lı yılların Amerika'sının yansıtılması olduğu düşünülmektedir.

“Aile: Anne-Baba İmgesi ve Geleneksel Değerler" (s. 79-91) adlı bölümde Plath ve Bellow da dolayısıyla bahse konu olan Sirça Fanus ve Herzog da, yani hem yaşamlarında hem de yapıtlarında ailenin ve taşıdıkları birtakım geleneksel değerlerin ve beklentilerin izlerinin her an görülebildiği ve zaman zaman derinleştiği belirtilmektedir. 1950 sonrası Amerikan romanında aile-toplum ilişkileri yapısının, endüstri ve kentleşme sürecinin tamamlanması sonucu yeniden değişime uğradığını düşünen yazar bunun başta Plath ve Bellow olmak üzere 
dönemin hemen bütün yazarlarını etkilediğini örneklerle sunmaya ve yine eserlerden örneklerle tüm bu kavramları dönemin şartları uyarınca açıklamaya çalışmaktadır. Kahramanların doğup büyüdükleri aile ortamı ve çevreden başlamak üzere yetiştikleri dönem, yaşadıkları kaygı, şaşkınlık, acı ve üzüntüler ve sonunda yaşadıkları çaresizlikler, kırgınlıklar her iki eserde de tüm çıplaklığıyla olduğu gibi ele alınmakta ve sonuçlar detaylı bir şekilde yine bu bölümde somut veriler 1şığında yorumlanmaktadır.

"Yabancılaşma ve Mazoşizm" (s. 91-100) bölümünde İkinci Dünya Savaş1 sonrasında sürekli değişen çevre koşulları, bireyi tüm değerlerinden mahrum bırakan acımasız kentsel yaşam, bilim-teknoloji ve madde merkezli düşünce sistemi, dönemin kargaşa ve bunalımları ile tüm bunların kaçınılmaz sonucu olarak kendini gösteren yabancılaşma ve mazoşizm konuları ele alınmaktadır. Yabancılaşma, ötekileşme, yalnızlaşma, mazoşizm gibi kavramların ne anlama geldiği, nasıl ortaya çıktığı gibi birçok konu alanın uzmanlarının görüşlerine de başvurularak verilmekte, bunların edebî yansımaları iki eser bağlamında sunulmaktadır.

"Yalnız, Yabancı ve Acı Çekenler" (s. 100-115) başlıklı bölümde, S. Bellow’un diğerlerine göre biraz farklılık gösteren yalnızlık ve yabancılaşması ile S. Plath'ın daha geniş boyutuyla ele alınan yalnızlık ve yabancılaşması karşılaştırılmakta Sırça Fanus ve Nefret bu anlamda güzel ve yetkin birer örnek olarak kullanılmaktadır. Yazar gerek Plath gerekse Bellow'un yalnızlık, yabancılık ve çaresizlik algılarını vermeden bu kavramların geçmişten günümüze hangi sosyal, siyasi ve kültürel süzgeçlerden geçerek bugüne geldiklerini açıklayarak Plath ve Bellow'un zaman, mekân ve kahramanlarını da buna göre betimlemektedir. Her iki yazarın kahramanının da kendi kendilerine zarar vererek kendilerini mağdur duruma soktuklarını ifade eden yazar bu yüzeysel benzerliğe rağmen iki yazar arasındaki farkın çektikleri acılar olduğuna değinmektedir.

“Ölüm Olgusu ve İnthhar” (s. 115-133) adlı bölümde ise kimine göre dünyanın kararması, her şeyin ve herkesin son bulması, kimine göre ise özgürlük ya da yeni bir başlangıç olarak algılanan ölümün farklı yorumlarına, algılarına dikkat çekilmekle birlikte gerek sanatta gerek edebiyatta ne denli etkin bir konu ve tema olduğu çok yönlü bir şekilde açıklanmaktadır. Bireysel olduğu kadar kitlesel olarak da görülen ölümün yapıtlarda genellikle savaş, nükleer kıyım, açlık, salgın, doğal afetle olabildiği gibi insanın öz yaşamına son vermesi yani intihar sonucu da olabileceği belirtilirken bu temanın sayısız bilimsel çalışmaya, farklı sanatsal ve edebî ürüne kaynaklık etmesi ve önemi açıklanmaktadır. Bazı temel yazınsal yapıtlarda bazen bir motif işlevi bazen de tema olarak algılanan ölüm ve intiharın tematolojik olarak inceleme konusu olduğunu vurgulayan yazar böyle bir çalışmaya psikanalitik-sosyolojik, tarihsel-felsefi ve yazınsal olarak farklı yaklaşımlar sunulabileceğini ifade etmektedir. Ölüm olgusu hakkında

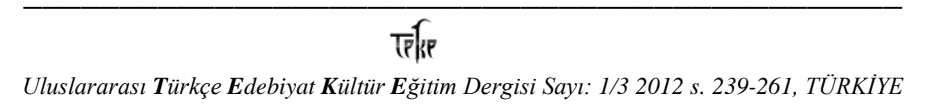


birbirinden farklı yapı ve özellikler göstermelerine rağmen her iki romanın da ölümü baştan sona kadar etkin biçimde hissettirdiklerini söyleyen yazar gerek Plath gerekse Bellow'dan vermiş olduğu örneklerle bunu somutlaştırmakta ve ilgililere başarılı bir şekilde sunmaktadır.

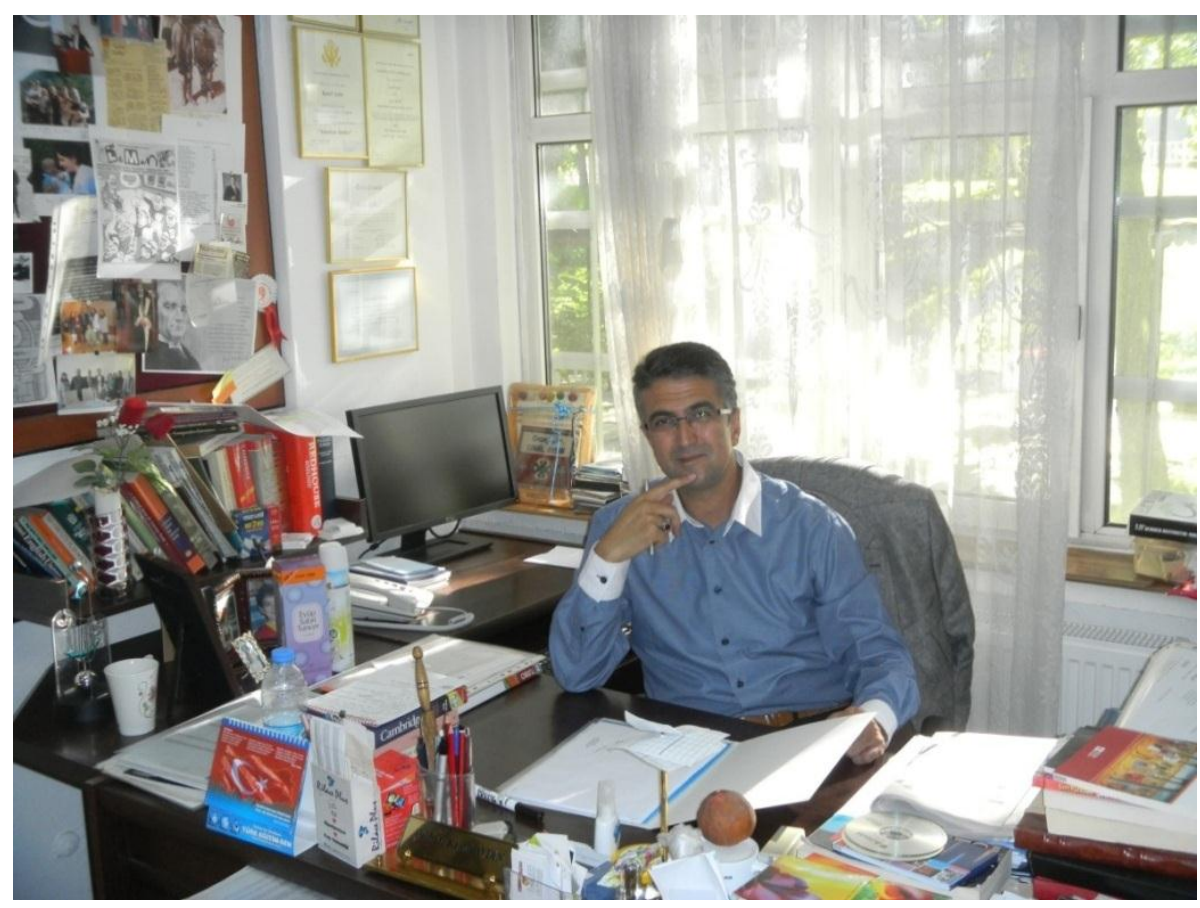

Fotoğraf 5: Prof. Dr. Kâmil AYDIN’ın çalı̧̧ma odasında çekilmiş bir görüntüsü

“Ölümcül Kimlikler” (s. 133-146) başlıklı bölümde yazar, gerek taşıdıkları entelektüel kimlikleri gerekse çeşitli bireysel, kültürel, etnik ve cinsel özelliklerden dolayı karşılaştıkları sorunlar karşısında takındıkları tavırları sonucu her iki edebiyatçının da ölümle ciddi bir şekilde ilgilendiklerini ve farklılık gösterse de tüm bunları eserlerine yansıttıklarını düşünmekte ve sözlerini şöyle sürdürmektedir:

S. Plath’ta daha çok kendine eziyet, acı çektirme veya zarar vermeyle birlikte intihar biçiminde görülürken, S. Bellow'da zaman zaman düşünce boyutunda yani somut bir eyleme dönüşmeyen düzeyde kalan intihar, Herzog'da da açıkça görüldüğü gibi başkalarına yönelik zarar verme veya öldürme olarak da karşımıza çıkabilmektedir. Diğer bir ifadeyle, Sırça Fanus ve Herzog'taki kahramanlar, çeşitli toplumsal bunalımlara alternatif bir çözüm olarak da gördükleri farklı bağlamlarda değerlendirilirler.

Her iki eserin de çeşitli yerlerinde karşımıza çıkan ölüm ve intihar duyguları bu bölümde örnek paragraflarla ele alınıp çok yönlü bir biçimde irdelenmekte ve yazarın marifetiyle dönemin ölüm, intihar algı ve anlayışları da olanca gerçekliğiyle okuyucuya ulaştırılmaktadır.

“Sonuç” (s. 146-153) bölümünde, 1950’li ve 1960'lı yılların panoraması çizilirken, çok başarılı iki eseri ve çok yetkin iki ismi tanıtılırken gerek Plath ve Bellow gerekse Sirça Fanus 
ve Nefret üzerine toparlayıcı, tamamlayıcı birtakım bilgiler verilmektedir. Entelektüel kavramının ve bu sıfata sahip olan bireyin taşıması gereken özelliklerin ifade edildiği bu bölümde yazar, insani birtakım değerlerden de yardım alarak eski-yeni dünya düzeninde insan ve insana ait olması gerekenleri başarılı bir şekilde betimlemektedir. Karşılaştırmalı edebiyata somut, güzel ve başarılı bir örnek olarak gösterilebilecek eserin bu bölümünde öncelikle yaşadıkları o kadar zorluğa, sıkıntıya rağmen çok kısa sürede çok büyük başarılara imza atan dünyaca ünlü iki yazar ve eserin sonuç değerlendirmelerine yer vermektedir. Bazı yargıların, benzerliklerin, ayrılıkların ve çeşitli farkındalıkların sunulması gayretiyle bölüm ve eser son bulmaktadır.

\subsection{Images of Turkey in Western Literature (Batı Edebiyatında Türkiye'nin Imajl):}

Images of Turkey in Western Literature (Batı Edebiyatında Türkiye'nin Imajı) (Cambridgeshire, 1999, 232 s.) adlı bu eser, "The British Council” için "Erzurum Atatürk Üniversitesi İngiliz Dili ve Edebiyatı Bölümü"nün iş birliğiyle "The Eothen Press" tarafından yayımlanmıştır.

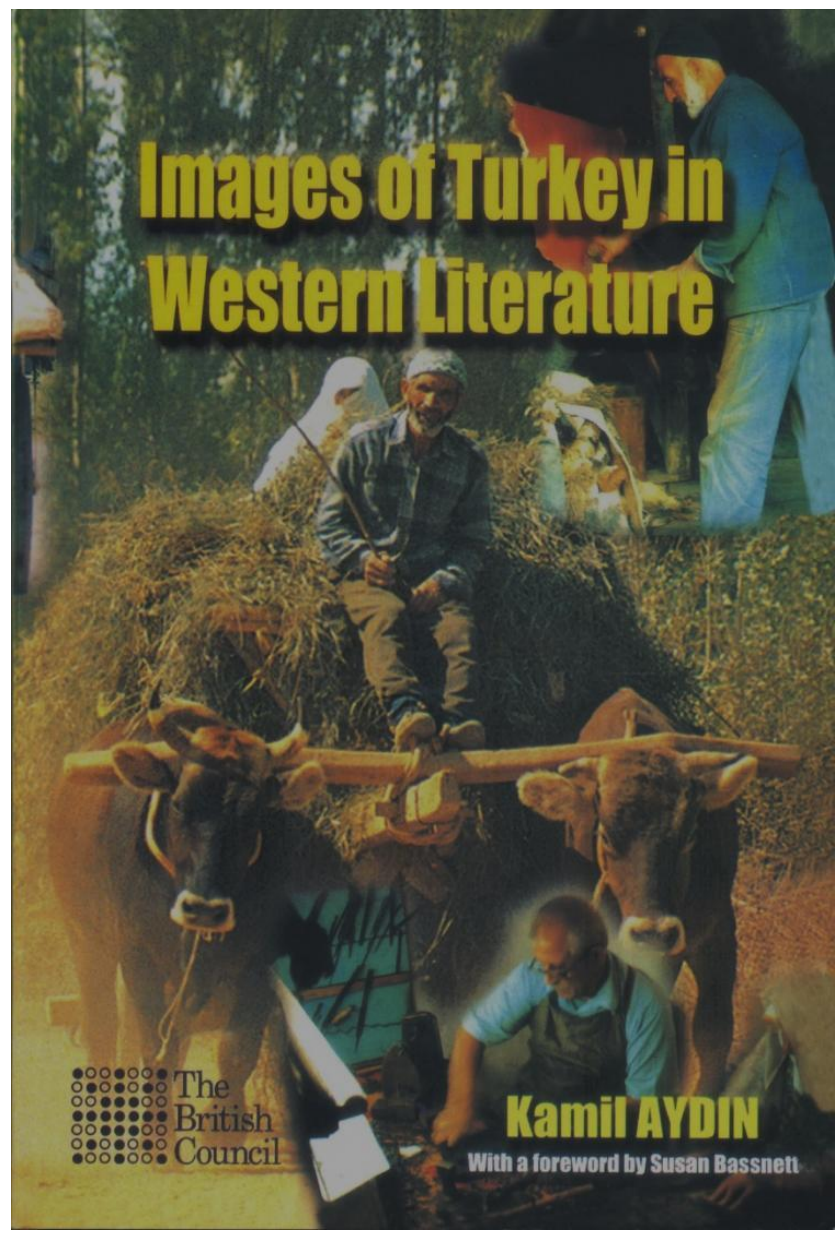

Fotoğraf 6: Images of Turkey in Western Literature adlı kitabın kapak görüntüsü

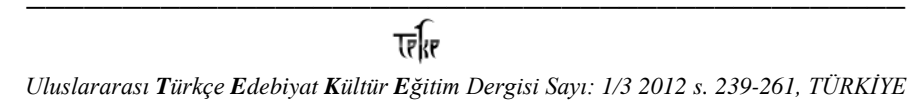


Sınırların hızla kalktığı günümüzde, kocaman bir köy hâlini alan dünyanın bilim ve teknoloji alanındaki hızlı ilerleyişi hiç şüphesiz kültür ve edebiyat alanlarına da olumlu-olumsuz etki etmektedir. Buna bağlı olarak doğu-batı yönlerinde de çeşitli değişme ve gelişmeler gözlenmektedir. Doğu ve Batı kavramlarının ele alınıp bunların sosyal, siyasal, kültürel ve edebî yönlerden detaylı bir çözümlemeye tabi tutulduğu, birbirleri için ne anlam ifade ettiklerinin, bunların sebep ve sonuçlarının araştırıldığı nüfuzlarının ortaya konduğu bu eserin bölümleri şu konuları içermektedir:

Eser, "About the Aouthor (Kâmil Aydın)" başlı̆ğ altında yazarın kısa öz geçmişinin sunulmasıyla başlayıp; karşılaştırmalı edebiyat alanının son dönem kilometre taşlarından biri olan Susan Bassnett'in yazar, eser ve konu hakkındaki düşüncelerini ifade ettiği, özgün çözümlemeler ve detaya inen değerlendirmeler yaptığı çok önemsenen ön sözüyle devam etmektedir.

"Foreword (Ön söz)" (s. III-V) adlı bölümde, kariyerine İtalya'da başlayan, Amerika Birleşik Devletler'inde birkaç üniversitede dersler veren, şu anda da Warwick Üniversitesi’nde Karşılaştırmalı Edebiyat alanında profesör olan Susan Bassnett'in eser hakkında yaptı̆̆ı değerlendirmelerden bahsedilmekte; eserin değindiği konular objektif bir karşılaştırmacı gözüyle değerlendirilmektedir. Bassnett, 20. yüzyılın sonlarında artan küresel kültürün, ulusal kültürlerin tekrar incelenmesine yol açtığını; Kâmil Aydın'ın da bu bağlamda bir eser ortaya koyduğunu belirtmektedir. Bassnett’a göre eseri diğer (benzerlerinden) ayıran özellik, eserin gezi yazısı ve dedektif hikâyesi gibi bazı farklı yazı türlerine odaklanmasından kaynaklanmaktadır.

"Introduction (Giriş)" (s. 1-43) bölümünde ise yazar, geçmiş yıllarda rastlanmasına rağmen 20. yüzyılda Türklerin Batı'daki imgeleri konusunda yazılmış, bu imajı inceleyen herhangi bir çalışmanın olmadığını belirtmektedir. Bu yönüyle eserin önemli bir eksikliği giderdiği ve bir ilk olma özelliği taşıdığı düşünülmektedir.

Kültür aktarımında çeviri çalışmalarının çok önemli olduğunu vurgulayan yazar, bu kitabı objektif bir bakış açısıyla kaleme aldığını ve Avrupalı olmayan özgün biri olmaya çalışarak yazdığını ifade etmektedir.

Oryantalistlerden ve eserlerinden bahseden yazar, bazı oryantalist yazarların Batı'y1 "ben”, Doğu'yu da "sen” olarak betimlediğini belirterek bu durumun gerçek ve yansız eleştiri yapmayı güçleştirdiğini düşünmektedir. Asyalı barbarları bir araya getirip İslam çatısı altında toplamaya çalışan birçok yazarın İslamiyet'i kötüleyen Hristiyanlığı öven yazılarından yakınmaktadır. Örneğin, Ütopya'nın yazarı Thomas Moore'un, Lalla Rookh: An Oriental Tale 
(1817) adlı eserinde Hz. Muhammed'den sihirbaz, şehvet tutkunu olarak bahsetmesi örneğinde olduğu gibi Avrupa'da özellikle 19. yüzyıl'da çocuklara devlet okullarında bile millî duyguları kabartan, öven şeylerin okutulduğuna değinmektedir.

Batılı eserlerin, Türkleri kaçakçı, casus, katliamcı vs. bir toplum olarak gördüğüne, böyle değerlendirdiğine dikkat çekmektedir. Osmanlının salt Türk, Türk'ün de salt Osmanlı olarak değerlendirmeye tabi tutulduğunu belirten yazar bu ve benzeri birçok konuyu, ilgili ve kabul gören kişi ve eserlerden hareketle bu bölümde başarılı bir şekilde irdelemektedir.

Bu önemli eserde Kâmil Aydın, özellikle 20. yüzyıla yoğunlaşarak Türkiye'nin ve Türklerin Batıdaki imajını incelemektedir. Orta Çağdaki Müslüman-Hristiyan karmaşasından Osmanlı'ya; oradan da günümüz Türkiye'sine uzanan uzun yolun batıdaki yansımalarını bizlere göstermekte; Türkiye'nin modern dünyadaki rolüne, turizm endüstrisinin Batıya sunduğu doğal ve tarihî güzelliklerine rağmen ülkemizin hâlâ devam eden olumsuz imajını sorgulamaktadır.

"An Assortment of Negative Imuxages (Olumsuz İmgelerin Sinıflandırılmas1)" (s. 43113) adlı birinci bölümde AYDIN, hem jeopolitik hem de kültürel açıdan Türkiye'nin sahip olduğu stratejik değerin düz yazı, gezi kitapları, dergiler ve sinema gibi çeşitli medya uzantılarında (genelde olumsuz bir şekilde) yansıdığından bahsetmektedir. Bu yansımaların genelde dinî suikastlar, askerî darbeler, uyuşturucu ticareti, terör eylemleri, tarihî eser kaçakçılı̆̆1, siyasi casusluk (ispiyonculuk), etnik soykırım ve işkence gibi tamamen olumsuz imgeler içerdiğini belirten yazar, bu imgelerin özellikle İstanbul'un fethi ile başladığını ileri sürmekte; bu doğrultuda da okuyucuya Agatha Christie'nin Doğu Ekspresi Cinayeti (1934), John Buchan'ın Doğudaki Sir (1916), William Shakespeare'in Othello (1603) adlı eserlerinden ve benzer birkaç eserden örnekler sunmaktadır.

"Images of Violence (Şiddet İmgeleri)" (s. 113-143) adlı ikinci bölümde ise, Rusya, Britanya, Almanya, İspanya gibi uzun bir tarihe sahip büyük imparatorlukların insanların zihninde hem olumlu hem de olumsuz imajlara sahip olduklarını; 700 yıllık Osmanlı İmparatorluğunun ve devamı olan Türkiye Cumhuriyeti’nin de aynı şartlara sahip olduğunu; ancak bazı figürlerin insanlar tarafından sürekli övülmesine, kahraman ilan edilmesine rağmen Türklerin, her nedense, sürekli barbar ve zalim resmedilmesine değinmektedir. Buna, 19. yüzy1l harem algılanışı olan "şehvet" ve "tutku”nun yanı sıra özellikle 20. yüzyılda meydana gelen bazı iç savaşların ve Birinci Dünya Savaşı esnasında Yunan ve Ermenilerle girilen savaşların neden olduğunu belirten yazar; Batı'da farklı şekilleriyle gösterilen bu olumsuz imgelerin katliamdan soykırıma, polis işkencesinden dayanılmaz hapishane koşullarına, uyuşturucu kaçakçılığından ispiyonculuğa kadar değişkenlik gösterdiğinden örneklerle bahsetmektedir.

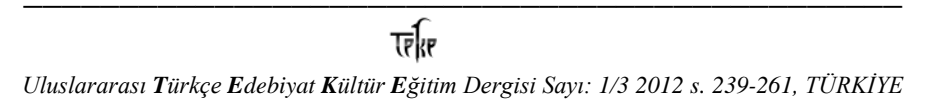

International Journal of Turkish Literature Culture Education Volume 1/3 2012 p. 239-261, TURKEY 
"Images of Exotic (Egzotik İmgeler)" (s. 143-163) isimli üçüncü bölümde, sıra dış1 ve egzotik arayışı içerisinde olan Batı'nın, özellikle de Britanya'nın, doğuya doğru keşiflere çıkmasından, bunun da gezi yazılarına yansımasından bahsetmektedir. Yazar, Türklerin zalim ve barbar olarak gösterilmelerinin yanı sıra William Gibson'1n Matrix Avısı (1984), Joan Fleming'in Zengin Olduğumda (1962) adlı eserlerinden örnekler vererek, doğudaki harem hikâyelerinin gezi yazılarına yansıyan şehvetli ve egzotik unsurlarına değinmektedir.

"First Impression of Turkey and the Turks (Türkiye'nin ve Türklerin İlk İzlenimi)" (s. 163-195) adlı dördüncü bölümde yazar aslında önceki üç bölümü özetlemekte; özellikle romanlara konu olan mekânlardaki olumsuzluklardan bahsetmektedir. Yazara göre Türkiye, özellikle de İstanbul, Doğu Ekspresine yolcu olanların durağıdır. Çünkü İstanbul, Asya'dan Avrupa'ya uzanan yolda, kıta değiştirmeden önceki son duraktır. Verilen örneklerde eser sahipleri bu şehirden; tembel insanların yaşadığı, dilencilerin adım başı karşınıza çıkabileceği bir şehir olarak bahsetmektedir. Kâmil Aydın, 20. yüzyılın ikinci yarısında bile, haçlı seferlerinden beri süregelen bu olumsuzlukların devam ettiğini dile getirmektedir.

Eserin, "Conclusion: From Verbal to Visual; Representations of Turkey into the Twenty-First Century (Sonuç: Yazından Görsele; 21. Yüzyıla Türkiye Yansımaları)" (s. 195215) adlı beşinci ve son bölümünde yazar, Türklere karşı olan ön yargının, Papa'nın dini kurtarma adına yaptığı haçlı seferiyle başladığını; yazdığı eserin 20. yüzyıl odaklı olmasına rağmen geçmişteki olaylardan kopmanın, geçmişle günümüzü ayrı tutarak karşılaştırma yapmanın imkânsız olduğunu belirtmektedir.

1453 ’te, İstanbul'un fethinin, Batı'nın Türklerle ilgilenmesi konusunda çok önemli bir ayak olduğuna değinen yazar, bu olumsuz imgelerin özellikle Avrupa Birliği'ne girmek için değişmek zorunda olacağına; kültürel bağlantıların, batı turizminin, yabancı dillerden Türkçeye, Türkçeden yabancı dillere yapılan çevirilerin, Türkiye ve Türkler aleyhine yüzyıllardır süregelen ön yargı, aşağılama gibi olumsuz hissiyatları ortadan kaldıracağına inanmaktadır.

\section{Kaynaklar:}

AYDIN, K. (1999). Karşılaştırmalı Edebiyat (Günümüz Postmodern Bağlamında Algılanışı). İstanbul: Birey Yayıncılık.

AYDIN, K. (1999). Images of Turkey in Western Literature. Cambridgeshire, England: The Eothen Press.

AYDIN, K. (2005). Entelektüel Yabancılar ve Ölümcül Kimlikler (Saul Bellow ve Sylvia Plath). Erzurum: Eser Ofset Matbaacılik.

CEVIZCİ, A. (2000). Felsefe Sözlügüu. İstanbul: Paradigma Yayınları.

ŞEN, S. (1995). Türk Aydını ve Kimlik Sorunu. İstanbul: Bağlam Yayınevi.

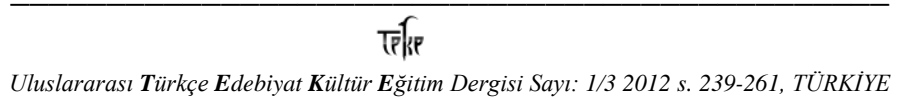

International Journal of Turkish Literature Culture Education Volume 1/3 2012 p. 239-261, TURKEY 